Article

\title{
Comparison of Droplet Deposition Control Efficacy on Phytophthora capsica and Aphids in the Processing Pepper Field of the Unmanned Aerial Vehicle and Knapsack Sprayer
}

\author{
Qinggang Xiao ${ }^{1}$, Rui Du ${ }^{1}$, Lin Yang ${ }^{1}$, Xiaoqiang Han ${ }^{1} * \mathbb{D}^{\mathbb{D}}$, Sifeng Zhao ${ }^{1}$, Guoqiang Zhang ${ }^{1}$, \\ Wei Fu ${ }^{2}$, Guobin Wang ${ }^{3}$ and Yubin Lan ${ }^{4}$ \\ 1 Key Laboratory of Oasis Agricultural Pest Management and Plant Protection Resources Utilization, \\ College of Agriculture, Shihezi University, Shihezi 832002, China; xqg@stu.shzu.edu.cn (Q.X.); \\ dr@stu.shzu.edu.cn (R.D.); yanglin@stu.shzu.edu.cn (L.Y.); zhsf_agr@shzu.edu.cn (S.Z.); \\ gqzhang@shzu.edu.cn (G.Z.) \\ 2 College of Mechanical and Electrical Engineering, Hainan University, Haikou 570228, China; \\ fuwei001@126.com \\ 3 Shandong Provincial Engineering Technology Research Center for Agricultural Aviation Intelligent \\ Equipment, College of Agricultural Engineering and Food Science, Shandong University of Technology, \\ Zibo 255022, China; guobinwang@stu.scau.edu.cn \\ 4 National Center for International Collaboration Research on Precision Agricultural Aviation Pesticide \\ spraying Technology (NPAAC), College of Engineering, South China Agricultural University, \\ Guangzhou 510642, China; ylan@scau.edu.cn \\ * Correspondence: hanshz@shzu.edu.cn; Tel.: +86-188-0993-1417
}

Received: 5 December 2019; Accepted: 25 January 2020; Published: 2 February 2020

\begin{abstract}
Processing pepper planting and processing have become an important red pillar industry in Xinjiang. With the continuous growth of processing pepper planting areas in Xinjiang, diseases and pests are increasing year by year. The aim of this study was to compare the droplet deposition and control efficiency of unmanned aerial vehicle (UAV) and electric air-pressure knapsack (EAP) sprayers on a processing pepper field. The UAV sprayer had a poor droplet coverage rate, droplet density, and deposition uniformity, but displayed the best deposition $\left(1.01 \mu \mathrm{g} / \mathrm{cm}^{2}\right.$, which was $98 \%$ more than the EAP sprayer). The control efficacy of the UAV sprayer on processing pepper fields with Phytophthora capsici and aphids was slightly lower than that of the EAP sprayer. When the UAV sprayer was used to control processing pepper diseases and pests, it could reduce the pesticide dosage on the premise of ensuring the control effect. Further study of the residue of high concentration pesticides in pepper fruit and environment sprayed by UAVs are needed.
\end{abstract}

Keywords: unmanned aerial vehicle; processing pepper; droplets deposition; Phytophthora capsici and aphids; control efficiency

\section{Introduction}

Peppers (Capsicum annuum L.), a member of the family, Solanaceae, are one of the most important vegetable crops worldwide [1]. Xinjiang is one of the main pepper-producing areas in China. Xinjiang has unique natural conditions that endow the dried pepper with early maturity and high quality. Peppers produced in Xinjiang have high popularity and market competitiveness in domestic and foreign markets [2]. In recent years, the processing pepper industry, which produces dry peppers, sauce, capsaicin, capsanthin, and other special processing varieties, has sprung up in Xinjiang and rapidly developed, becoming a new industry of a characteristic economy. It plays an increasingly 
significant role in promoting the adjustment of the agricultural industrial structure and the increase of farmers' income [3]. Processing pepper planting have become an important red pillar industry in Xinjiang [4,5]. With the continuous growth of processing pepper planting areas in Xinjiang, diseases and pests are increasing year by year [6]. Phytophthora blight of pepper is caused by the oomycete Phytophthora capsici and is one of the most destructive diseases in the world [7,8]. P. capsici attacks the roots, stems, leaves, and fruits of pepper plants $[9,10]$. Aphis gossypii Glover is a small stinging insect pest and is the most significant pest affecting peppers. The harm of aphids to peppers is now serious [11,12]. The adults and nymphs of aphids suck the juice of pepper plants, which makes these plants' leaves curl and turn yellow. They also secrete nectar to cover the leaves of the peppers, leading to coal pollution disease, which affects the photosynthesis of pepper plants. Aphids are the main vector of virus disease transmission, which seriously affects the yield and quality of peppers [12].

Boom sprayers and electric air-pressure knapsack (EAP) sprayers are widely used for processing pepper fields. However, using boom sprayers with ground machinery leads to problems, such as rolling pepper plants, hitting processing pepper fruit, and pulling pepper branches, which reduce the yield and quality of peppers [13]. Moreover, the EAP sprayer has low efficiency and poor atomization effects. This has become a bottleneck and a technical problem restricting the improvement in the quality and efficiency of the pepper industry in Xinjiang. In order to solve this bottleneck problem and improve the shortage of the crop protection equipment supply, unmanned aerial vehicles (UAVs) have been rapidly developed in Xinjiang for pesticide application [14,15]. UAVs, as emerging plant protection machinery, have high operational efficiency and reduce pepper production costs. Further, precise variable-rate pesticide spraying with UAVs could be realized according to crop type to reduce pesticide dosages and pesticide residues [16-20]. According to incomplete statistics, nearly 10,000 crop protection UAVs are used in Xinjiang. The rapid and efficient operation of UAVs makes them suitable for processing pepper pesticide spraying. In recent years, there have been many reports in the research of plant protection UAVs on wheat, rice, corn, cotton, and other crops. However, research on spraying pesticides by UAVs in processing pepper fields has not been reported $[14,15]$. In this study, we compared the spraying effect of EAP sprayer and UAV sprayer, the droplet distribution and control efficacy were studied. This study focused on the feasibility of UAV spraying pesticide in processing pepper field, and further explored the UAV spraying technology to pest control in processing pepper field.

\section{Materials and Methods}

In order to investigate the advantage and shortcoming of the UAV sprayer, we selected DJI T16 UAV sprayer and EAP sprayer for field spray deposition, control efficacy on processing pepper P. capsici and aphids. The spray deposition was compared from three aspects: the total amount of deposition, deposition uniformity, droplets penetration in the canopy and characterization of the deposition (including droplet size, number of spray deposits and the area of coverage).

\subsection{Instruments and Equipment}

The aviation platform used was the T16 UAV (SZ DJI Technology Co., Ltd., Shenzhen, China; Figure 1). This UAV is Global Navigation Satellite System and Real-Time Kinematic (GNSS RTK) navigation technology, with a flying height and flying velocity both accurately controlled to remain within the centimeter level. The UAV is powered by an AB2-17500 mAh (51.8V) Li-Po electric air-pressure knapsack (SZ DJI Technology Co., Ltd., Shenzhen, China). The UAV has six rotors, the volume of the water tank is $16 \mathrm{~L}$, and the payload is $15 \mathrm{~kg}$. The flying time is $10 \mathrm{~min}$ with a full tank. The nozzles are XR11001VS. The pressure range in the actual work was $0.2-0.35 \mathrm{MPa}$, and the flow rate was 2.2-2.4 L/min (droplet size 130-250 $\mu \mathrm{m}$ ). The accuracy of the flight height and flight velocity were controlled by a well-trained operator. The flight height was $2.0 \mathrm{~m}$, and the effective spraying width was $5 \mathrm{~m}$. The spray volume of all nozzles output is around $15 \mathrm{~L} / \mathrm{ha}$. The $3 \mathrm{WBD}-20$ electric air-pressure knapsack (EAP) sprayer (Taizhou Kaiserdom Machinery Co., Led., Taizhou, China) 
is equipped with double hollow cone nozzles. The tank capacity is $20 \mathrm{~L}$, the working pressure of the double cone nozzle is $0.1-0.2 \mathrm{Mpa}$, and the flow rate is $1.2 \mathrm{~L} / \mathrm{min}$. The spray volume of one nozzle output is around $300 \mathrm{~L} / \mathrm{ha}$.

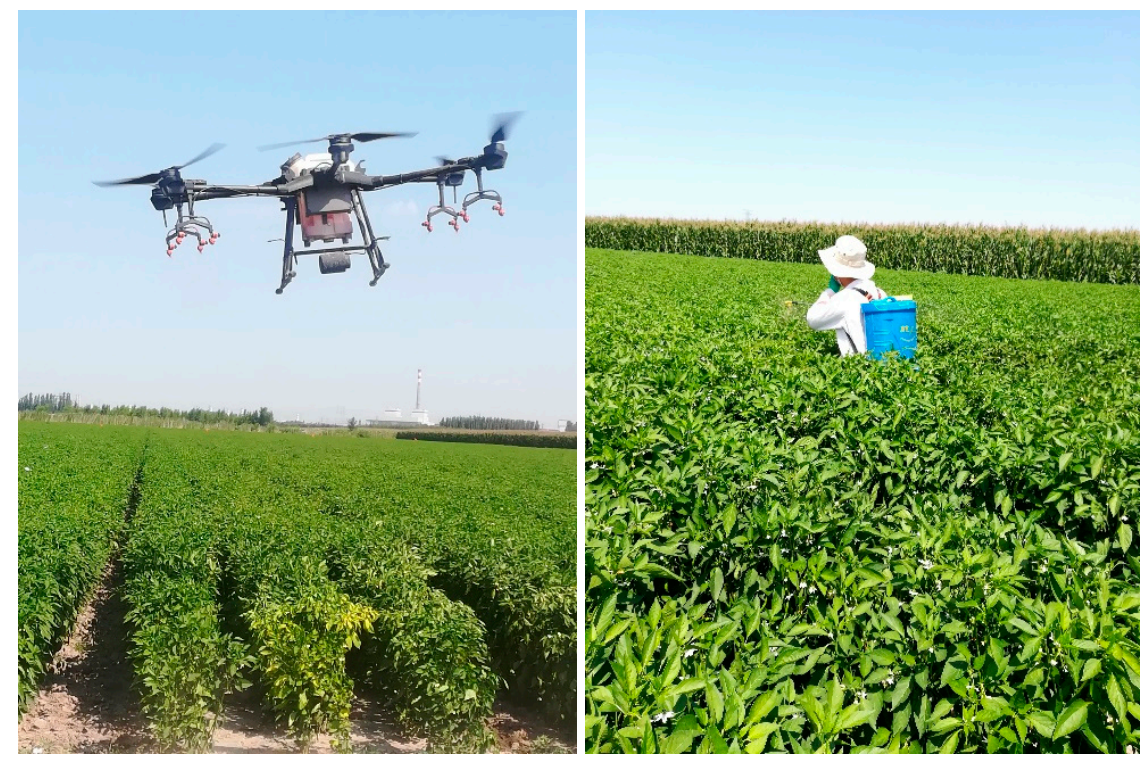

Figure 1. The unmanned aerial vehicle (UAV) sprayer (T16 UAV) and the electric air-pressure knapsack sprayer (3WBD-20).

The electronic balance, BSA224S-CW, was produced by Sartorius, Göttingen, Germany. The handheld Weather Station (NK5500L) was produced by Nielsen-Kellerman Company, Boothwyn, PA, USA. The Infinite 200 PRO ELISA instrument was produced by Tecan Trading AG, Switzerland. The Filescan2500 scanner was produced by Shanghai Zhongjing Technology Co., Ltd., Shanghai, China. The experimental materials were as follows: metal rods $(1.2 \mathrm{~m})$, kromekote cards $(30 \times 80 \mathrm{~mm})$, and filter papers $(d=70 \mathrm{~mm}$ ) (Ge Biotechnology (Hangzhou) Co., Ltd., Hangzhou, China).

\subsection{Experimental Design}

\subsubsection{Field Plots}

The experiment was carried out in the Beiquan town of Xinjiang Production and Construction Corps, Shihezi, $\left(44^{\circ} 23^{\prime} 11^{\prime \prime}\right.$ N, 86 $6^{\prime} 11^{\prime \prime}$ E), Xinjiang Uygur Autonomous Region, China, in 2019. The experimental field had a middle-level fertilizer and had processing peppers that had been planted for two years. Processing peppers (Honglong 18) were sown on 12 April 2019, using a mechanical processing pepper-picking planting model with a wide film that planted 6 lines $(10 \mathrm{~cm}+66 \mathrm{~cm})$ at 210,000 processing pepper plants/ha. Furthermore, there was drip irrigation under a plastic film.

The first spraying was conducted 12:00-15:00 on 26 June 2019 (UTC+8) to control Phytophthora capsici Leonian. At that time, the processing peppers were at the initial flowering stage, and the average plant height was $49 \mathrm{~cm}$. The second spraying was conducted 11:50-15:00 on 18 July 2019 (UTC+8) to control Aphis gossypii Glover. At that time, the processing peppers were at the full fruiting period, and the average plant height was $88 \mathrm{~cm}$. There was no precipitation during spraying.

\subsubsection{Treatment}

There were 5 treatments in each spraying (Table 1 ). Treatments 1,2 , and 3 were sprayed with the UAV sprayer, and the pesticide dosage was $1,1 / 2$, and $1 / 3$ times the field recommendation, respectively. Treatment 4 was used with the EAP sprayer, and the pesticide dosage was the same as the field recommendation. Treatment 5 was used as a control. The area of each treatment was $0.27 \mathrm{ha}$, and the 
amount of allura red (Zhejiang Gigagold Pigment Technology Co., Ltd., Wenzhou, China) was 300 g/ha. 72\% cymoxanil•mancozeb wettable powder (WP) (Shanghai DuPont agrochemical Co., Ltd., Shanghai, China) were used for controlling pepper blight, and 20\% flonicamid suspension concentrate (SC) (Jiangsu Kesheng Group Co., Ltd., Yancheng, China) was used for controlling pepper aphids.

Table 1. Treatment for insecticide dosage.

\begin{tabular}{|c|c|c|c|c|c|}
\hline \multirow[b]{2}{*}{ Treatment } & \multirow{2}{*}{$\begin{array}{c}\text { Field } \\
\text { Recommendation } \\
\text { Times }\end{array}$} & 26 June 2019 & 18 July 2019 & \multirow{2}{*}{$\begin{array}{l}\text { Spray } \\
\text { Volume } \\
\text { (L/ha) }\end{array}$} & \multirow[b]{2}{*}{ Sprayer } \\
\hline & & $\begin{array}{l}\text { 72\% Cymoxanil•Mancozeb } \\
\text { (a. i. g/ha) }\end{array}$ & $\begin{array}{l}20 \% \text { Flonicamid } \\
\quad \text { (a. i. g/ha) }\end{array}$ & & \\
\hline 1 & 1 & 540 & 37.5 & 15 & \\
\hline 2 & $1 / 2$ & 270 & 18.75 & 15 & UAV \\
\hline 3 & $1 / 3$ & 180 & 12.5 & 15 & \\
\hline 4 & 1 & 540 & 37.5 & 300 & EAP \\
\hline 5 & 0 & - & - & 0 & - \\
\hline
\end{tabular}

\subsubsection{Droplet Distribution}

The experiment consisted of five treatments, and the spray deposition was tested. The spray deposition was measured in an area of $110 \times 120 \mathrm{~m}$ (Figure 2A). The sample layout was repeated three times, with adjacent repetition occurring $20 \mathrm{~m}$ apart. Each plot had dimensions of $14 \times 120 \mathrm{~m}$. Ten-meter buffer zones were set between plots to avoid drift pollution (Figure 2A). Sample collectors at each sample site consisted of one kromekote card (Figure 2B) and one filter paper $(d=70 \mathrm{~mm}$; Figure 2B). On June 26, 2019, the kromekote card and filter were placed at heights of 0, 5, 30, and $45 \mathrm{~cm}$ from the ground; on July 18, 2019, the paper and filter papers were $0,10,55$, and $80 \mathrm{~cm}$ from the ground. The kromekote card was used to evaluate the following deposition characteristics: (i) coverage, (ii) the number of spray impacts/stains, and (iii) the dimensions of the impact/stains [21,22]. The filter papers were used to evaluate the droplet deposition. The kromekote cards and filter papers were fixed to processing pepper plants using plastic clips [21,22]. Nearly $30 \mathrm{~s}$ after spraying, all kromekote cards and filter papers were removed and placed in ziplock bags along with a label describing the treatment, replication, and site information. Samples were placed into light-proof sealed boxes immediately after collection and transported to the laboratory for analysis [18].

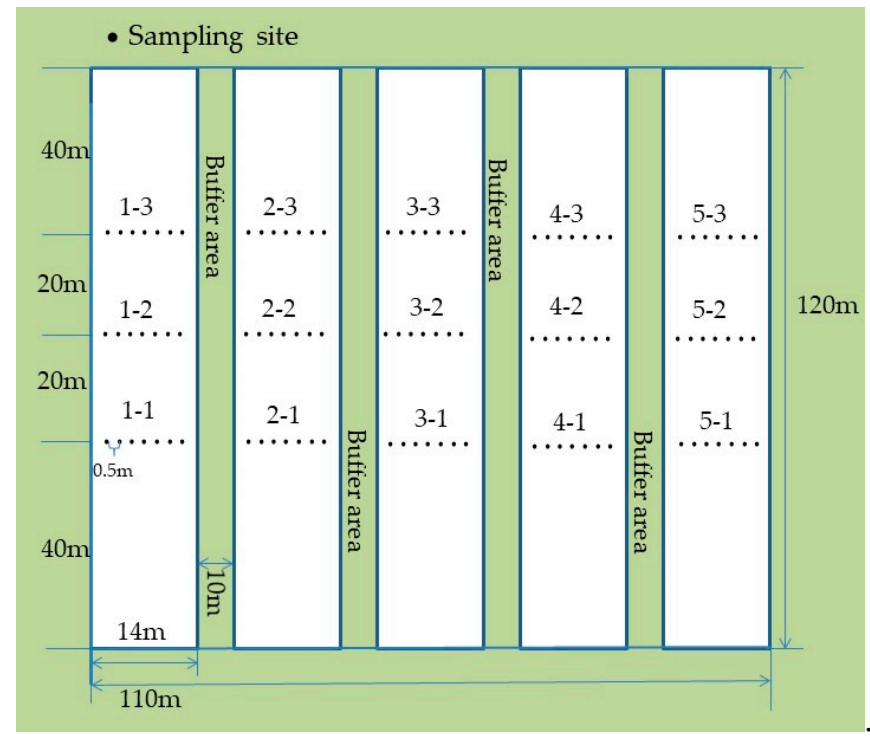

(A)

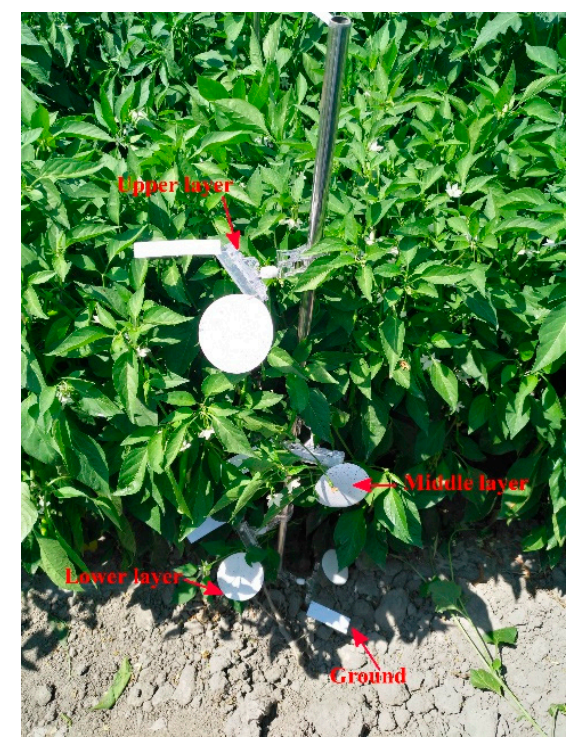

(B)

Figure 2. (A) The experimental layout of each treatment and (B) the placement of kromekote cards and filter papers at each sampling position within the processing pepper canopy. 
In the laboratory, the kromekote cards were scanned at a resolution of $600 \mathrm{dpi}$ with a scanner. ImageJ software (ImageJ 1.3 8, National Institutes of Health, Bethesda, MD, USA) was used to extract droplet deposits in the digital image for analysis of the droplet size, the number of spray deposits, and the area of coverage [16]. To characterize the uniformity of droplet deposition between spray width, the uniformity of droplet deposition was measured by the coefficient of variance $(\mathrm{CV})$ of droplet deposition densities at different locations of the processing pepper plants within the UAV sprayer's effective spray width. The $C V$ of the droplet deposition density was calculated by Equations (1) and (2) $[16,23]$ :

$$
\begin{gathered}
C V=\frac{S}{\bar{X}} \times 100 \% \\
S=\sqrt{\sum_{i=1}^{n}\left(X_{i}-\bar{X}\right)^{2} /(n-1)}
\end{gathered}
$$

where $S$ is the sample standard deviation, $X_{i}$ is the number of droplets per unit area at each collection point, $\mathrm{n}$ is the number of collection points, and $\bar{X}$ is the average.

Each filter paper was washed with $5 \mathrm{~mL}$ of distilled water and kept in separate bags. Each bag was shaken for $1 \mathrm{~min}$, and the papers were allowed to soak for $1 \mathrm{~h}$. Afterwards, the washing solution was removed from the bag, and the colorant concentration was measured at $514 \mathrm{~nm}$ with an ELISA instrument. The solution obtained from washing the unsprayed strips of filter paper were used as the baseline solution. Droplet distribution was determined in accordance with the standard curve of allura red. Equations (3)-(5) were used to calculate the deposition of droplets on the cotton plants [24]:

$$
\mathrm{Ds}=(\mathrm{F} /(\mathrm{V} \times \mathrm{S})) \times 1.67
$$

where Ds is the volume of spraying per unit area $\left(\mu \mathrm{L} / \mathrm{cm}^{2}\right), V$ is the flight speed $(\mathrm{m} / \mathrm{s}), \mathrm{S}$ is the spraying width $(\mathrm{m})$, and $\mathrm{F}$ is the spray flow $(\mathrm{L} / \mathrm{min})$.

$$
\mathrm{Dd}=((\mathrm{Ce} \times \mathrm{V}) / \mathrm{CS}) / \mathrm{A}
$$

where Dd is the droplet deposition $\left(\mu \mathrm{L} / \mathrm{cm}^{2}\right)$, Ce is the ELISA instrument reading and the allura red concentration $(\mu \mathrm{g} / \mathrm{L}), \mathrm{V}$ is the volume of the dilution liquid used to dilute the tracer from the collector $(\mathrm{mL}), \mathrm{CS}$ is the concentration of the tracer in spray $(\mathrm{g} / \mathrm{L})$, and A is the area of the filter paper $\left(\mathrm{cm}^{2}\right)$.

$$
\mathrm{R} \%=\mathrm{Dd} / \mathrm{Ds} \times 100 \%
$$

where $\mathrm{R} \%$ is the effective deposition rate, Dd is the droplet deposition $\left(\mu \mathrm{L} / \mathrm{cm}^{2}\right)$, and Ds is the volume of spraying per unit area $\left(\mu \mathrm{L} / \mathrm{cm}^{2}\right)$.

To ensure the accuracy of the measurement data, the allura red $(20 \mathrm{mg})$ was dissolved in $100 \mathrm{~mL}$ of water and diluted to $1 \mathrm{~L}$ to a final concentration of $20 \mathrm{mg} / \mathrm{L}$. The mother liquid was then diluted to $0.1,0.2,0.5,1.0$, and $2.0 \mathrm{mg} / \mathrm{L}$. The absorbance values were measured at $510 \mathrm{~nm}$ in triplicate per concentration by using an ELISA instrument. The standard curve of allura red was created on the basis of the absorbance values of the six solutions [16], as shown in Figure 3. The linear fitting of the standard solution concentration and absorbance, where correlation index R2 $=0.997$, and the concentration and absorbance for the relationship were as follows:

$$
Y=0.0238 X+0.0431
$$

where $X$ is the absorbance of the allura red solution, and $Y$ is the concentration of the allura red solution in $\mathrm{mg} / \mathrm{L}$. 


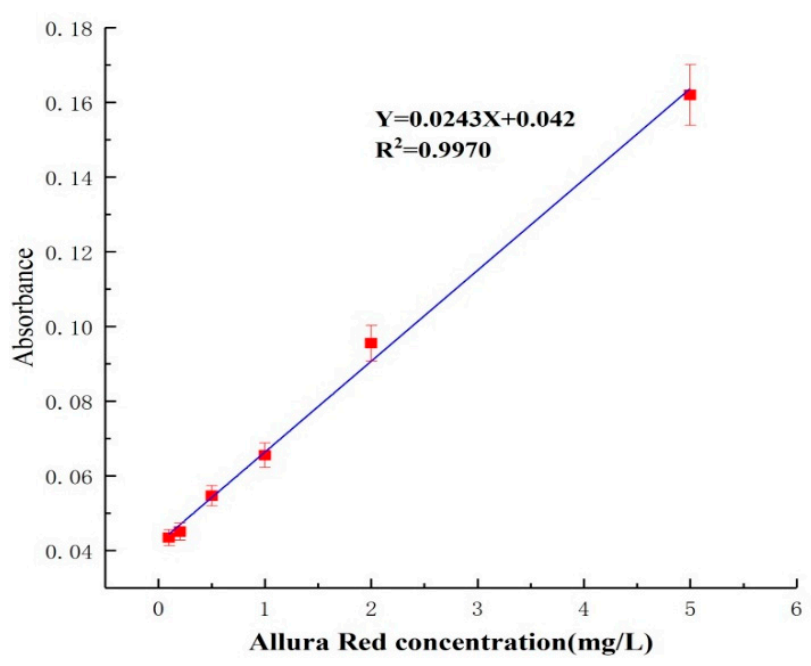

Figure 3. Standard curve of the allura red solution.

\subsubsection{Control efficacy}

In order to evaluate the spraying effect of the UAV sprayer in plant protection, we selected the processing pepper disease incidence andaphid number as field test targets.

P. capsici: Disease severity was evaluated on a 0-9 scale according to an evaluation system of Yang et al. [25] with slight modifications, where $0=$ there is no evidence of infection; $1=\leq 5 \%$ of the stem surface is diseased; $3=5-15 \%$ of the stem surface is diseased; $5=16-25 \%$ of the stem surface is diseased; $7=26-50 \%$ of the stem surface is diseased; $9=\geq 50 \%$ of the stem surface is diseased. The disease index and control efficacy for each fungicide were calculated according to the Equations (6) and (7) [26].

$$
\begin{gathered}
\mathrm{DI}=\frac{\sum n \times m}{9 \times p} \times 100 \\
\mathrm{Ce}=\frac{D c-D t}{D c} \times 100 \%
\end{gathered}
$$

where DI is the disease index, $\mathrm{n}$ is the number of a certain disease level surveyed, $\mathrm{m}$ is the disease level corresponding to $\mathrm{n}$, and $\mathrm{p}$ is the total number of surveys; Ce is the control efficiency, Dc is the disease index in the treatment area, and $\mathrm{Dt}$ is the disease index in the control area.

Aphids: The survey and recording of the aphid population were performed in accordance with criteria for pesticide field efficacy tests. To investigate the control effect of pesticide application on aphids, the parallel-jump method was used to survey the population numbers of cotton aphids and spider mites in each zone prior to spraying and at 5, 10, 15, and 20 days after spraying. Each zone was subjected to a five-point survey using five processing pepper plants for each point. The total number of aphids for a 10-point survey using one processing pepper plant for each point was counted. The overall control effect against aphids was quantified without considering the types or growth stages of aphids. The dropping rate and control effect were obtained on the basis of the population numbers of live insects in each zone before and after spraying, in accordance with Equations (8) and (9).

$$
\begin{gathered}
\mathrm{D}=\left(\left(\mathrm{N}_{\mathrm{a}}-\mathrm{N}_{\mathrm{b}}\right) / \mathrm{N}\right) \times 100 \% \\
\mathrm{CE}=\left(\mathrm{D}_{\mathrm{a}}-\mathrm{D}_{\mathrm{b}}\right) /\left(100-\mathrm{D}_{\mathrm{b}}\right) \times 100 \%
\end{gathered}
$$

where $D$ is the decline rate of the insect mouth. $N_{a}$ is the number of live insects before spraying. $N_{b}$ is the number of live insects after spraying. CE is the control efficiency. $D_{a}$ is the decline rate of the insect mouth in the treatment area, and $\mathrm{D}_{\mathrm{b}}$ is the decline rate of the insect mouth in the control area. 


\subsection{Data Statistics and Processing}

All data were analyzed by Origin 9.1 (Origin 9.1 origin Lab, Northampton, MA, USA) and SPSS 22 (SPSS Inc, an IBM Company, Chicago, IL, USA) statistical software. By comparing via the mean one-way ANOVA (one-way ANOVA) method, the LSD (least significant difference) was selected. The interval was set to $95 \%$, and $p<0.05$ was considered a significant difference between the two groups.

\section{Results and Discussion}

\subsection{Droplet Deposition in Processing Peppers}

\subsubsection{Droplet Coverage}

The effect of UAV sprayers on the droplet coverage in pepper plants is shown in Figure 4. The droplet coverage rate when spraying with the EAP sprayer twice was significantly higher than that of the UAV sprayer $(21.12 \%$ vs. $1.83 \%$ and $18.59 \%$ vs. $1.43 \%)$. This is because the spraying volume of the EAP sprayer ( $300 \mathrm{~L} / \mathrm{ha})$ was 20 times that of the UAV sprayer $(15 \mathrm{~L} / \mathrm{ha})$. This shows that the amount of spray has a significant impact on the coverage of pesticide droplets, and the coverage of pesticide droplets is positively correlated with the amount of spray. Meng et al. also reached the same conclusion on the spray effect of cotton defoliant [27]. The droplet coverage rate in the middle and lower parts of the second spraying was significantly lower than that of the first spraying. The main reason was that the interval between the two sprayings was 22 days, which was in the stage of the fastest growth of processing peppers. The leaf area index of processing peppers increased rapidly, which led to a decrease of the droplet coverage rate in the middle and lower layer of the canopy. For the double spraying, the coverage rate of the upper and middle layers was significantly better than that of the lower layer (both the UAV and EAP sprayers). This was because the leaves in the middle and upper parts of the processing peppers were densely staggered, which affects the penetration of droplets.

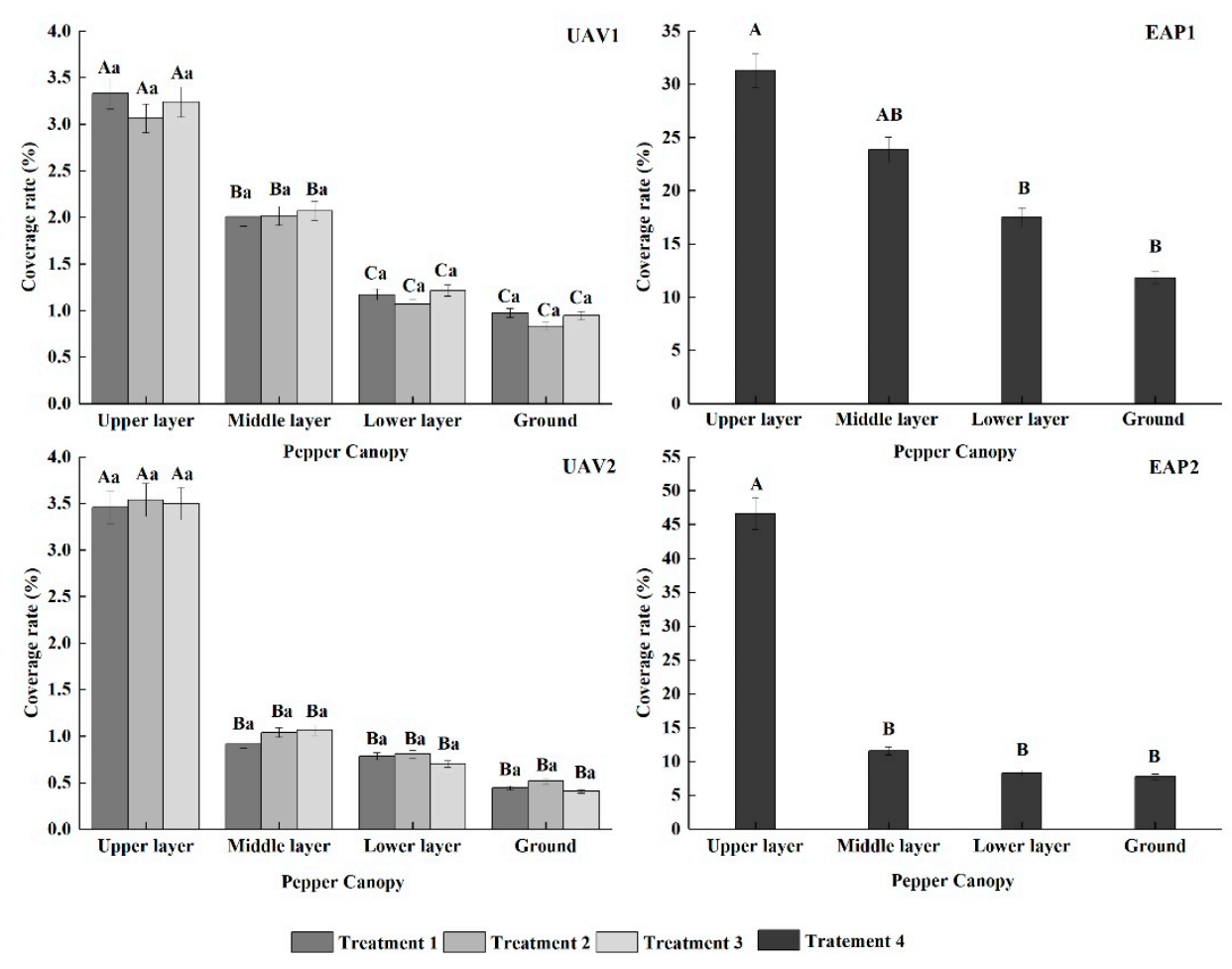

Figure 4. Effect of UAV and EAP sprayers on droplet coverage of processing pepper plants. UAV1: the first spraying to control P. capsici; EAP1: the first spraying to control P. capsici; UAV2: the second spraying to control the aphids; EAP2: the second spraying to control the aphids. 
As many pests and diseases occur on the bottom of plants, the droplets penetrability is crucial to enhance control efficacy [28]. The results from our study proved that the penetration of the droplets of UAV is still worse than EAP sprayer. This result is similar to the results of Wang et al. [29]. There are many factors that affect droplet penetration. Zhu et al. [28], the spray deposits decreased dramatically from the top to the bottom of the canopies and also tended to linearly decrease as the leaf area index increase. Due to the overlap and the block of the blades at the later growth stage of the wheat, the depositions on the lower parts were far less than top parts. Wang et al. compared four kinds of UAV sprayer and found the flight height and the flight speed had a pronounced impact on droplet penetrability [30]. Meanwhile, wind field is one of the important factors affecting the distribution characteristics of aerial spraying droplet deposition. Chen et al. testified that the vertically downward wind had a significant effect on the penetrability [31].

It is worth noting that both the UAV and EAP sprayers could detect droplet information on the ground, indicating that both sprayers led to pesticide loss.

The size, number, and concentration of droplets had an important influence on the field efficacy of the pesticide [32]. Table 2 shows the effect of the UAV and EAP sprayers on the size of the droplets on the processing pepper leaves. In both sprayings, the droplet size of the EAP sprayer was significantly larger than that of the UAV, with an average particle size of 2.2 to 5.15 times that of the UAV. This is due to the poor atomization effect of the nozzle of the EAP sprayer. Some studies have concluded that small droplets more easily penetrate the middle and lower parts of the canopy [33], while others have shown that large droplets do this more easily [34]. In this study, the droplet size of different parts of the processing pepper canopy was basically the same, indicating that the droplet size had no significant effect on the penetration of droplets.

Table 2. The effect of UAV and EAP sprayers on droplet size.

\begin{tabular}{|c|c|c|c|c|c|}
\hline \multirow{2}{*}{ Spraying Date } & \multirow{2}{*}{ Canopy } & \multirow{2}{*}{ Treatment } & \multicolumn{3}{|c|}{ Droplet Size } \\
\hline & & & Dv10 & Dv50 & Dv90 \\
\hline \multirow{12}{*}{26 June 2019} & \multirow{4}{*}{ Upper layer } & 1 & $163.6 \pm 13.7 b$ & $282.7 \pm 31.1 b$ & $427.3 \pm 59.0 b$ \\
\hline & & 2 & $160.1 \pm 23.0 \mathrm{~b}$ & $300.4 \pm 53.1 b$ & $491.2 \pm 69.6 b$ \\
\hline & & 3 & $163.1 \pm 32.8 b$ & $295.0 \pm 64.0 \mathrm{~b}$ & $493.3 \pm 146.0 b$ \\
\hline & & 4 & $546.1 \pm 232.5 a$ & $1123.1 \pm 417.6 \mathrm{a}$ & $1866.3 \pm 710.1 \mathrm{a}$ \\
\hline & \multirow{4}{*}{ Middle layer } & 1 & $166.0 \pm 23.0 b$ & $271.1 \pm 29.6 b$ & $407.7 \pm 55.1 b$ \\
\hline & & 2 & $158.7 \pm 22.6 b$ & $272.9 \pm 41.3 b$ & $467.8 \pm 112.6 b$ \\
\hline & & 3 & $153.5 \pm 28.9 b$ & $265.3 \pm 50.7 b$ & $418.6 \pm 88.9 b$ \\
\hline & & 4 & $391.5 \pm 123.1 \mathrm{a}$ & $829.1 \pm 188.6 a$ & $1302.6 \pm 265.7 a$ \\
\hline & \multirow{4}{*}{ Lower layer } & 1 & $160.6 \pm 21.0 c$ & $257.4 \pm 39.2 b$ & $368.8 \pm 79.1 b c$ \\
\hline & & 2 & $156.1 \pm 20.6 b c$ & $259.7 \pm 31.1 b$ & $449.5 \pm 125.1 b$ \\
\hline & & 3 & $144.1 \pm 15.6 b$ & $258.3 \pm 40.5 b$ & $398.5 \pm 67.0 c$ \\
\hline & & 4 & $312.9 \pm 88.9 a$ & $726.3 \pm 185.0 \mathrm{a}$ & $1131.6 \pm 236.4 a$ \\
\hline \multirow{12}{*}{18 July 2019} & \multirow{4}{*}{ Upper layer } & 1 & $180.5 \pm 32.7 b$ & $306.4 \pm 49.3 b$ & $481.3 \pm 119.9 b$ \\
\hline & & 2 & $177.3 \pm 33.1 b$ & $312.2 \pm 41.1 b$ & $485.1 \pm 79.1 b$ \\
\hline & & 3 & $175.1 \pm 42.3 \mathrm{~b}$ & $303.9 \pm 66.9 b$ & $479.9 \pm 92.0 b$ \\
\hline & & 4 & $711.9 \pm 25.0 \mathrm{a}$ & $1606.3 \pm 48.8 \mathrm{a}$ & $2485.1 \pm 92.0 \mathrm{a}$ \\
\hline & \multirow{4}{*}{ Middle layer } & 1 & $167.6 \pm 26.9 b$ & $283.3 \pm 44.2 b$ & $395.0 \pm 94.9 b$ \\
\hline & & 2 & $166.1 \pm 27.6 b$ & $282.4 \pm 45.5 b$ & $396.7 \pm 49.3 b$ \\
\hline & & 3 & $166.9 \pm 42.3 b$ & $277.6 \pm 66.9 b$ & $390.3 \pm 89.4 b$ \\
\hline & & 4 & $209.1 \pm 62.4 \mathrm{a}$ & $374.0 \pm 84.3 \mathrm{a}$ & $650.9 \pm 163.5 a$ \\
\hline & \multirow{4}{*}{ Lower layer } & 1 & $162.9 \pm 48.5 b$ & $271.6 \pm 57.5 b$ & $365.8 \pm 67.0 b$ \\
\hline & & 2 & $159.5 \pm 33.6 b$ & $270.4 \pm 78.4 b$ & $368.4 \pm 88.0 b$ \\
\hline & & 3 & $157.3 \pm 26.8 b$ & $262.9 \pm 30.4 b$ & $345.2 \pm 35.8 b$ \\
\hline & & 4 & $206.4 \pm 48.0 \mathrm{a}$ & $340.2 \pm 78.5 a$ & $514.3 \pm 132.9 a$ \\
\hline
\end{tabular}

Nate: Values followed by the same letter in the column do not differ statistically ( $p<0.05$; Duncan's Test). 


\subsubsection{Droplet Density}

With the same spray volume, the droplet density of the UAV sprayer had no significant difference in the same canopy (Figure 5). This result was consistent with the research conclusion of Yuan and Wang [32]. Their research showed that the spray volume had a significant impact on the droplet, and with the increase in spray volume, the droplet density showed an increasing trend [32]. The $72 \%$ cymoxanil•mancozeb WP was sprayed with the UAV sprayer to control P. capsici. There were significant differences among the upper, middle, and lower layers of the processing pepper canopy. The average droplet density of the upper layer sprayed with the UAV sprayer was $34.91 / \mathrm{cm}^{2}$, that of the middle and lower layers was $23.03 / \mathrm{cm}^{2}$ and $15.06 / \mathrm{cm}^{2}$, respectively, and that of the ground was $9.50 / \mathrm{cm}^{2}$. Meanwhile, the average droplet density was $60.65 / \mathrm{cm}^{2}, 57.16 / \mathrm{cm}^{2}$, and $48.24 / \mathrm{cm}^{2}$, respectively, for the upper, middle, and lowers layer sprayed with the EAP sprayer. The average droplet density of the EAP sprayer was $52.39 / \mathrm{cm}^{2}$, which is 2.54 times that of the UAV sprayer $\left(20.62 / \mathrm{cm}^{2}\right)$. Moreover, the droplet density of the EAP sprayer had no significant difference at all layers. The average coefficient of variation $(58.34 \%<60 \%)$ of the EAP sprayer was the smallest, and the uniformity was the best in the first treatment (Table 3). In the second spraying, 20\% Flutamide SC was used, and there was no significant difference in the spray density of the UAV sprayer in the same canopy, which was the same as the conclusion of the first spraying. The average coefficient of variation $(57.67 \%<60 \%)$ of the EAP sprayer showed that the droplet density was more affected by droplet uniformity, and the larger the canopy index, the worse the uniformity of droplets (Table 3).
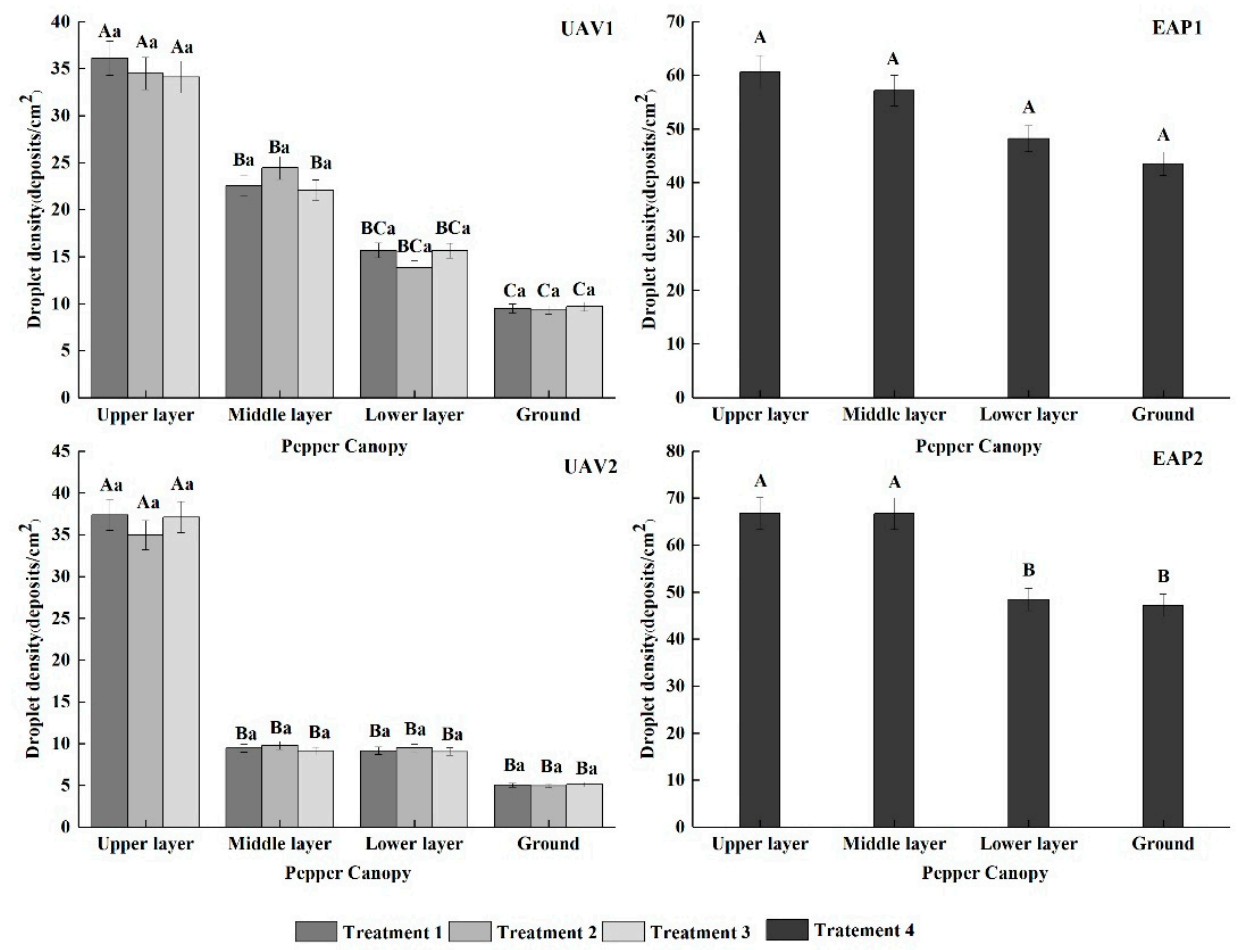

Figure 5. Effect of UAV and EAP sprayer on droplet density. UAV1: the first spraying to control P. capsici (UAV sprayer); EAP1: the first spraying to control P. capsici (EAP sprayer); UAV2: the second spraying to control the aphids (UAV sprayer); EAP2: The second spraying to control the aphids (EAP sprayer).

\subsubsection{The Uniformity of the Deposition}

The uniformity of the deposition is also very important for controlling pests and diseases. To comprehensively evaluate the droplet deposition distribution in the processing pepper canopy, the coefficient of variation $(\mathrm{CV})$ of the droplet deposition characteristics (droplet density and coverage rate) was calculated to characterize the droplet distribution uniformity after the addition of alkyl 
ethyl sulfonate (Table 3). For low volume spraying, the relevant quality indicators could be achieved when the droplet distribution uniformity was less than $60 \%$ [35]. For UAV spraying, the $C V$ of the droplet distribution for the upper layer of the processing pepper canopy was better than that of the middle and lower layers. Moreover, the deposition uniformity of the second spraying was significantly lower than that of the first spraying. This was due to the high canopy index of the processing pepper plant, especially in the late growth stage. The leaves were staggered and dense, which seriously affects the penetration and even the distribution of droplets. The uniformity of the deposition distribution of the UAV sprayer was influenced by many factors, such as the types [30], the flight accuracy, the flight parameters [20], the spraying system, the biased downwash wind, and the meteorological condition [31]. Moreover, the uniformity of the droplets sprayed by the EAP sprayer was higher than that of the UAV spraying. Wang et al. reported that the deposition uniformity of the EAP sprayer depended on the stability of the traveling speed along the spraying route and on the regularity of the arm movement of the operators [29].

Table 3. Effect of the droplet distribution on the coefficient of variation.

\begin{tabular}{cccccc}
\hline \multirow{2}{*}{ Spraying Date } & \multirow{2}{*}{ Treatment } & \multicolumn{4}{c}{$C V$ (\%) } \\
\cline { 3 - 6 } & & Upper Layer & Middle Layer & Lower Layer & Average \\
\hline \multirow{3}{*}{ 26 June 2019 } & 1 & 57.72 & 64.24 & 67.90 & 63.29 \\
& 2 & 48.41 & 70.24 & 88.69 & 69.11 \\
& 3 & 64.86 & 71.90 & 80.34 & 72.37 \\
& 4 & 50.49 & 63.06 & 60.85 & 58.13 \\
\hline \multirow{3}{*}{ 18 July 2019 } & 1 & 64.79 & 77.75 & 77.45 & 73.33 \\
& 2 & 41.01 & 80.99 & 94.80 & 72.27 \\
& 3 & 52.60 & 90.74 & 90.94 & 78.09 \\
& 4 & 49.26 & 64.50 & 60.68 & 58.15 \\
\hline
\end{tabular}

\subsubsection{Droplet Penetrability}

The $72 \%$ cymoxanilømancozeb WP and 20\% flutamide SC was sprayed to control the P. capsici and the aphids. The droplet deposition is shown in Figure 6. An analysis of the deposition of the upper layer of the processing pepper canopy shows that the deposition of the low-volume UAV sprayer was significantly higher than that of the EAP sprayer (Figure 6A1). The greatest deposition was achieved with the UAV sprayer with $1.01 \mu \mathrm{g} / \mathrm{cm}^{2}$, which was $98 \%$ more than the EAP sprayer (Figure 6A1). The main reason for the higher upper layer of the processing pepper deposition of the UAV sprayer may be that fine droplets were better retained in the upper canopy $[36,37]$. The droplet coverage and density of the EAP sprayer were significantly higher than those of the UAV, but the deposition rate was very low. The deposition of the three treatments sprayed by the UAV on the lower layer of processing peppers was $41.80-51.18 \%$ that on the upper layer, which indicated that the spray had good penetration. For the second spraying, the deposition of the UAV sprayer was 2.48 times that of EPA sprayer. Remarkably, the deposition of the three treatments sprayed by the UAV on the lower layer of processing peppers was $16.73-25.24 \%$ that of the upper layer, which was significantly lower than the first spraying. This was due to the high canopy index of the processing pepper plant, especially in the late growth stage. The leaves were staggered and dense, which seriously affects the penetration and even the distribution of droplets. The EAP sprayer showed similar results. 


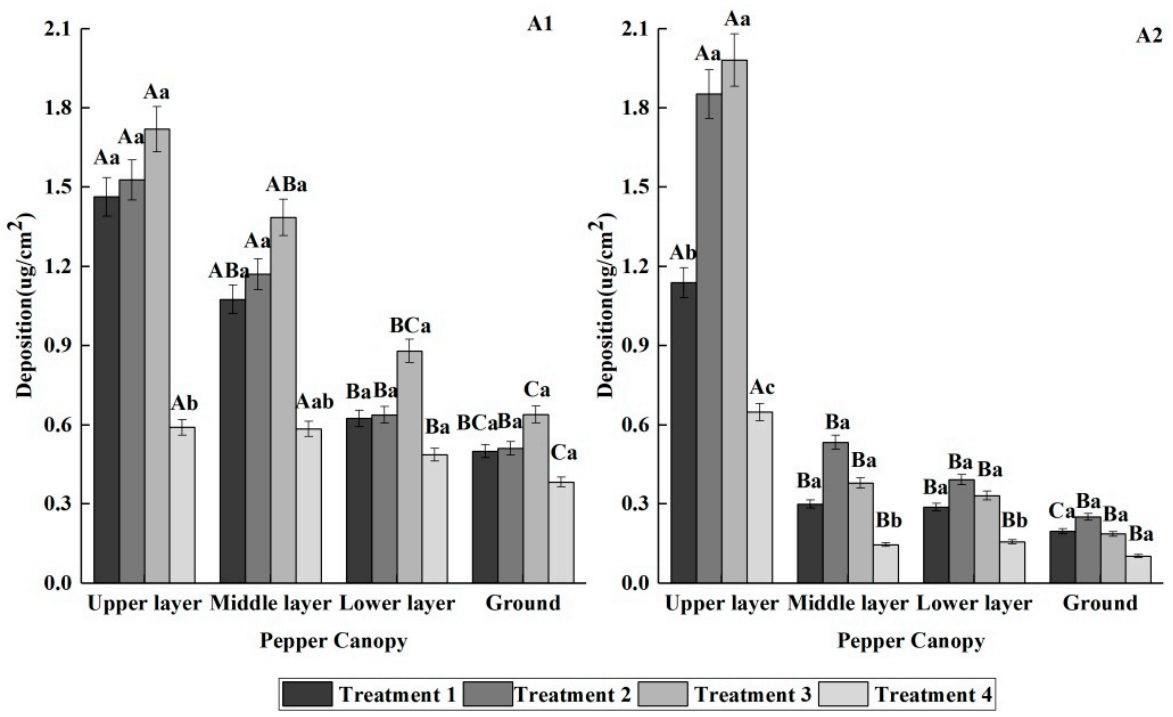

Figure 6. Effect of the UAV and EAP sprayers on droplet penetrability. A1: the first spraying to control the P. capsici; A2: the second spraying to control the aphids. Treatments 1,2 , and 3 were sprayed by the UAV sprayer, and the pesticide dosage was $1,1 / 2$, and $1 / 3$ times the field recommendation, respectively. Treatment 4 was used with the EAP sprayer, and the pesticide dosage was the same as the field recommendation.

\subsection{Control of the P. capsici and the Aphids}

The control efficacy of the two sprayers applying $72 \%$ cymoxanil•mancozeb WP on processing peppers with $P$. capsici is indicated in Figure 7A1. The EAP sprayer showed better control efficacy on processing peppers with $P$. capsici, and the control efficacy was beyond $95 \% 20$ days after spraying. Among the three treatments with the UAV sprayer, Treatment 2, i.e., 1/2 times the field recommendation dosage, showed the worst control efficacy $(81.44 \%)$. The control efficacy of Treatment 3, i.e., $1 / 3$ times the field recommendation dosage, displayed the best control efficacy $(94.34 \%)$. Deposit structure plays a major role in control efficacy $[29,38]$. According to the results of the deposition, the ESP sprayer had better deposition uniformity, which benefits the control of processing peppers with $P$. capsici. The larger area of coverage and a larger number of spray deposits increased the odds of interaction between active ingredients and pathogens. The control efficacy of the two sprayers applying $20 \%$ flutamide SC on processing peppers with aphids is indicated in Figure 7A2. Similar to processing peppers with P. capsici control, the effect of the EAP sprayer on aphids was better than that of the UAV spraying. The control efficacy five days after spraying was beyond $80 \%$. It is worth noting that the control of diseases and insect pests via UAV spraying was better when the dosage of the pesticide was $1 / 3$ times the field recommendation dosage. It was thus shown that UAV spraying has a significant effect on the reduction of pesticide application efficiency. 


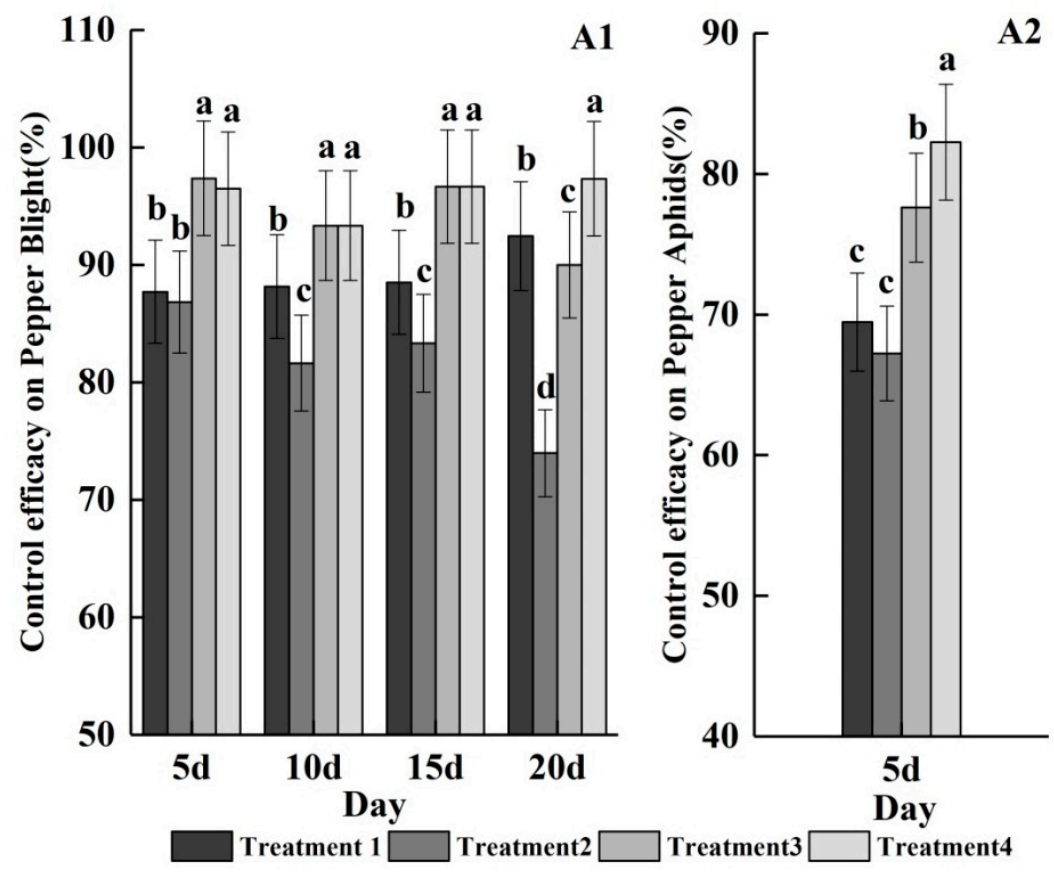

Figure 7. Control efficacy (\%) of UAV and EAP sprayers against processing peppers $P$. capsici and aphids. A1: the first spraying to control P. capsici; A2: the second spraying to control the aphids. Treatments 1, 2 , and 3 were sprayed with a UAV sprayer, and the pesticide dosage was 1, 1/2, and 1/3 times the field recommendation, respectively. Treatment 4 was used as an EAP sprayer, and the pesticide dosage was the same as the field recommendation.

\section{Conclusions}

In this study, UAV and EAP sprayers were used for pesticide applications in processing pepper fields. The total deposition on the plants, the uniformity of the deposition, droplet penetrability, the characteristics of the deposition, and the control efficacy of the processing pepper field with P. capsici and aphids were compared. The conclusions are as follows:

(1) The UAV sprayer had a poor droplet coverage rate, droplet density, and deposition uniformity. The greatest deposition was achieved with the UAV sprayer with $1.01 \mu \mathrm{g} / \mathrm{cm}^{2}$, which was $98 \%$ more than that achieved with the EAP sprayer.

(2) Although the spray deposition characterizations of the UAV sprayer were lower than that of the EAP sprayer, the control efficacy of UAV sprayer applications of $72 \%$ cymoxanil•mancozeb WP and $20 \%$ flutamide SC on processing pepper fields with P. capsici and aphids, compared with that of EAP sprayer applications, was slightly lower.

(3) The growth stage of processing peppers had a significant impact on droplet characteristics and on the control effect of pesticides.

(4) UAV spraying has a significant effect on the reduction of pesticide application efficiency.

The experiments demonstrated the feasibility and high efficiency of UAV sprayers in processing pepper fields. However, the deposition uniformity and the droplet penetrability of the UAV need to be improved. Due to the lower coverage and poor deposition uniformity, effective measures, such as optimizing the spraying system or adding adjuvant in the tank, which can improve deposition uniformity and penetrability, will be needed. It is also necessary to study the residue of high-concentration pesticides in pepper fruits and environments treated with a UAV sprayer.

Author Contributions: X.H. and S.Z. conceived and designed the experiments; Q.X., R.D., L.Y., and G.W. performed the field experiments; Q.X., X.H., and G.Z. analyzed the data; X.H. wrote the paper; W.F. and Y.L. conceived the research and revised the manuscript. All authors have read and agreed to the published version of the manuscript. 
Funding: We acknowledge that this work was financially supported by the Xinjiang Production and Construction Corps Major Scientific and Technological Projects (2018AA010-03) and the National Key Research and Development Program of China (2016YFD0200700).

Acknowledgments: The authors are grateful to SZ DJI Technology Co., Ltd., for providing a plant protection UAV.

Conflicts of Interest: The authors declare that there is no conflict of interest.

\section{References}

1. Howard, L.R.; Talcott, S.T.; Brenes, C.H.; Villalon, B. Changes in phytochemical and antioxidant activity of selected pepper cultivars (Capsicum species) as influenced by maturity. J. Agric. Food Chem. 2000, 48, 1713-1720. [CrossRef] [PubMed]

2. Song, W.S.; Yuan, F.N.; Zhang, X.G. The status quo and development trend of Dried-Fruit-Processing hot pepper industry in Xinjiang. Pepper Mag. 2010, 3, 5-8. (In Chinese)

3. Wu, Y.T.; Wu, Y.; Du, M.Y.; Cheng, F.F.; Wang, L.Y.; Yin, N.; Liu, W.B. Research status and development trend of chili sauce industry in Xinjiang. China Brewing 2019, 38, 1-4. (In Chinese)

4. Ge, J.F.; Yan, T.; Ouyang, W.; Tian, Z. The current situation and Development Countermeasures of pepper industry in Xinjiang. J. China Capsicum 2010, 8, 8-10, 16. (In Chinese)

5. Zhao, Z.X.; Qiao, L.F.; Li, Z.W. Thoughts and Countermeasures of developing capsicum characteristic industry in Xinjiang. Xinjiang Agric. Sci. Technol. 2012, 3, 4-5. (In Chinese)

6. Fang, X.C.; Qu, H.L.; Zhao, S.F.; Guo, K.F.; Ma, M. Pathogen Identification of Processing Chili Pepper Root Rot Disease in Xinjiang. North. Hortic. 2016, 15, 108-112. (In Chinese)

7. Zhang, Y.L.; Jia, Q.L.; Li, D.W.; Wang, J.E.; Yin, Y.X.; Gong, Z.H. Characteristic of the Pepper CaRGA2 Gene in Defense Responses against Phytophthora capsici Leonian. Int. J. Mol. Sci. 2013, 14, 8985-9004. [CrossRef]

8. Hausbeck, M.K.; Lamour, K.H. Phytophthora capsici on vegetable crops: Research progress and management challenges. Plant Dis. 2004, 88, 1292-1303. [CrossRef]

9. Simón, A.; García, C.; Pascual, F.; Ruiz, L.; Janssen, D. The Influence of Crop Habitat and Control Strategies on Pepper Viruses in Andalusia (Spain). Horticulturae 2016, 2, 15. [CrossRef]

10. He, Y.M.; Liu, K.K.; Zhang, H.X.; Cheng, G.X.; Ali, M.; Ul Haq, S.; Wei, A.M.; Gong, Z.H. Contribution of CaBPM4, a BTB Domain-Containing Gene, to the Response of Pepper to Phytophthora capsici Infection and Abiotic Stresses. Agronomy 2019, 9, 417. [CrossRef]

11. Chen, J.; Fan, Y.; Wang, T.; Zhang, C.; Qiu, Z.; He, Y. Automatic Segmentation and Counting of Aphid Nymphs on Leaves Using Convolutional Neural Networks. Agronomy 2018, 8, 129. [CrossRef]

12. Luo, S.L.; Zhang, S.J.; Zhang Sun, D.T. Investigation on aphid species of Capsicum annuum. J. Biol. 2003, 20, 22-24. (In Chinese)

13. Xiao, Q.G.; Xin, F.; Lou, Z.X.; Zhou, T.T.; Wang, G.B.; Han, X.Q.; Lan, Y.B.; Fu, W. Effect of Aviation Spray Adjuvants on Defoliant Droplet Deposition and Cotton Defoliation Efficacy Sprayed by Unmanned Aerial Vehicles. Agronomy 2019, 9, 217. [CrossRef]

14. He, X.K.; Jane, B.; Andreas, H.; Jan, L. Recent development of unmanned aerial vehicle for plant protection in East Asia. Int. J. Agric. Biol. Eng. 2017, 10, 18-30.

15. Yuan, H.Z.; Xue, X.Y.; Yan, X.J.; Qin, W.C.; Kong, X.; Zhou, Y.Y.; Wang, M.; Gao, S.C. Applications and prospects in the unmanned aerial system for low-altitude and low-volume spray in crop protection. Plant Prot. 2018, 44, 152-158. (In Chinese)

16. Wang, G.B.; Lan, Y.B.; Qi, X.X.; Chen, P.C.; Hewitt, A.J.; Han, Y.X. Field evaluation of an unmanned aerial vehicle (UAV) sprayer: Effect of spray volume on deposition and the control of pests and disease in wheat. Pest Manag. Sci. 2019, 9, 218. [CrossRef]

17. Wang, J.; Lan, Y.B.; Zhang, H.H.; Zhang, Y.L.; Wen, S.; Yao, W.X.; Deng, J.J. Drift and deposition of pesticide applied by UAV on pineapple plants under different meteorological conditions. Int. J. Agric. Biol. Eng. 2018, 11, 5-12. [CrossRef]

18. Lou, Z.X.; Xin, F.; Han, X.Q.; Lan, Y.B.; Duan, T.Z.; Fu, W. Effect of Unmanned Aerial Vehicle Flight Height on Droplet Distribution, Drift and Control of Cotton Aphids and Spider Mites. Agronomy 2018, 8, 187. [CrossRef]

19. Xin, F.; Zhao, J.; Zhou, Y.T.; Wang, G.B.; Han, X.Q.; Fu, W.; Deng, J.Z.; Lan, Y.B. Effects of Dosage and Spraying Volume on Cotton Defoliants Efficacy: A Case Study Based on Application of Unmanned Aerial Vehicles. Agronomy 2018, 8, 85. [CrossRef] 
20. Qin, W.C.; Qiu, B.J.; Xue, X.Y.; Chen, C.; Xu, Z.F.; Zhou, Q.Q. Droplet deposition and control effect of insecticides sprayed with an unmanned aerial vehicle against plant hoppers. Crop Prot. 2016, 85, 79-88. [CrossRef]

21. Zhu, H.P.; Salyani, M.; Fox, R.D. A portable scanning system for evaluation of spray deposit distribution. Comput. Electron. Agric. 2011, 76, 38-43. [CrossRef]

22. Berger-Neto, A.; Jaccoud-Filho, D.S.; Wutzki, C.R. Effect of spray droplet size, spray volume and fungicide on the control of white mold in soybeans. Corp Prot. 2017, 92, 190-197. [CrossRef]

23. Massinon, M.; De Cock, N.; Forster, W.A.; Nairn, J.J.; McCue, S.W.; Zabkiewicz, J.A.; Lebeau, F. Spray droplet impaction outcomes for different plant species and spray formulations. Crop Prot. 2017, 99, 65-75. [CrossRef]

24. Wang, C.L.; He, X.K.; Wang, X.N. Testing method of spatial pesticide spraying deposition quality balance for unmanned aerial vehicle. Trans. CSAE 2016, 32, 54-61. (In Chinese) [CrossRef]

25. Yang, Y.Q.; Li, X.Q.; Meng, F.; Lan, B. Establishment of a resistance-identification method on asparagus stem blight and evaluation of Asparagus officinalis germplasms. Acta Phytopath. Sin. 2012, 42, 649-654. (In Chinese)

26. Dai, Y.L.; Gan, L.; Ruan, H.C.; Shi, N.N.; Du, Y.X.; Liao, L.; Wei, Z.X.; Teng, Z.Y.; Chen, F.R.; Yang, X.J. Sensitivity of Cochliobolus heterostrophus to three demethylation inhibitor fungicides, propiconazole, diniconazole and prochloraz, and their efficacy against southern corn leaf blight in Fujian Province, China. Eur. J. Plant Pathol. 2018, 152, 447-459.

27. Meng, Y.H.; Song, J.L.; Lan, Y.B.; Mei, G.Y.; Liang, Z.J.; Han, Y.X. Harvest aids efficacy applied by unmanned aerial vehicles on cotton crop. Ind. Crops Prod. 2019, 140, 111645. [CrossRef]

28. Zhu, H.; Dorner, J.W.; Rowland, D.L.; Derksen, R.C.; Ozkan, H.E. Spray penetration into peanut canopies with hydraulic nozzle tips. Biosyst. Eng. 2004, 87, 275-283. [CrossRef]

29. Wang, G.B.; Lan, Y.B.; Yuan, H.Z.; Qi, H.X.; Chen, P.C.; Ouyang, F.; Han, Y.X. Comparison of Spray Deposition, Control Efficacy on Wheat Aphids and Working Efficiency in the Wheat Field of the Unmanned Aerial Vehicle with Boom Sprayer and Two Conventional Knapsack Sprayers. Appl. Sci. 2019, 9, 218. [CrossRef]

30. Wang, S.L.; Song, J.L.; He, X.K.; Song, L.; Wang, X.N.; Wang, C.L.; Wang, Z.C.; Ling, Y. Performances evaluation of four typical unmanned aerial vehicles used for pesticide application in China. Int. J. Agric. Biol. Eng. 2017, 10, 22-31.

31. Chen, S.D.; Lan, Y.B.; Li, J.Y.; Zhou, Z.Y.; Liu, A.M.; Mao, Y.D. Effect of wind field below unmanned helicopter on droplet deposition distribution of aerial spraying. Int. J. Agric. Biol. Eng. 2017, 10, 67-77.

32. Yuan, H.Z.; Wang, G.B. Effects of droplet size and deposition density on field efficacy of pesticides. Plant Prot. 2015, 41, 9-16. (In Chinese)

33. Moritz, K. Effect of droplet size and carrier volume on performance of foliage-applied herbicides. Crop Prot. 1994, 13, 163-178.

34. Derksen, R.C.; Zhu, H.; Ozkan, H.E.; Hammond, R.B.; Dorrance, A.E.; Spongberg, A.L. Determining the influence of spray quality, nozzle type volume, and air-assisted application strategies on deposition of pesticides in soybean canopy. Trans. ASABE 2008, 51, 1529-1537. [CrossRef]

35. Civil Aviation Industry Standards of the People's Republic of China: Quality Indexes of Agricultural Aviation Operation: Part 1: Spraying Operation MH/T 1002.1-2016 [S]; Standards Press of China: Beijing, China. (In Chinese)

36. Hislop, E.C.; Western, N.M.; Butler, R. Experimental air-assisted spraying of a maturing cereal crop under controlled conditions. Crop Prot. 1995, 14, 19-26. [CrossRef]

37. Ebert, T.A.; Taylor, R.A.J.; Downer, R.A.; Hall, F.R. Deposit structure and efficacy of pesticide application. 2: Trichoplusia ni control on cabbage with fipronil. Pestic. Sci. 1999, 55, 793-798. [CrossRef]

38. Ebert, T.A.; Taylor, R.A.J.; Downer, R.A.; Hall, F.R. Deposit structure and efficacy of pesticide application. 1: Interactions between deposit size, toxicant concentration and deposit number. Pestic. Sci. 1999, 55, 783-792. [CrossRef]

(C) 2020 by the authors. Licensee MDPI, Basel, Switzerland. This article is an open access article distributed under the terms and conditions of the Creative Commons Attribution (CC BY) license (http://creativecommons.org/licenses/by/4.0/). 